\title{
The importance of acknowledging statisticians as named authors
}

\author{
Reinhard Vonthein ${ }^{1} \cdot$ Catey Bunce ${ }^{2} \cdot$ Diana Epstein $^{3} \cdot$ Paul Henry John Donachie $^{4}$
}

Received: 23 March 2020 / Revised: 23 March 2020 / Accepted: 28 March 2020 / Published online: 15 April 2020

(C) The Author(s) 2020

Many papers published in the field of Clinical and Experimental Ophthalmology use statistical methods, hence the importance of statisticians on the editorial board of our journal Graefe's Archive for Clinical and Experimental Ophthalmology.

Our responsibility is focused on ensuring that methods are reproducible, the analysis is appropriate, and the results are useful (e.g., reporting standard deviations for use with planning future studies). Advanced statistical methods are rarely applied, and perhaps one reason for this is the suggestion that statisticians cannot be named authors or a restriction upon the number of statisticians that may be included as co-authors. In the editorial published in 2011 [1], it was noted: "In Graefe's, a statistician can be a named author." We would now wish to go further than this and encourage authors to engage statisticians where possible.

What would happen if statisticians were acknowledged as named authors?

First of all, we believe that there would be an increase in the use of appropriate statistical methods. One of the most frequent reasons for paper rejection is suboptimal or even incorrect statistics. In our journal, a total of 76 papers have been sent for statistical peer review during the past 2 years (2018

Reinhard Vonthein

reinhard.vonthein@uni-luebeck.de

1 Institut für Medizinische Biometrie und Statistik, Universität zu Lübeck, Universitätsklinikum Schleswig-Holstein, Campus Lübeck, Ratzeburger Allee 160, 23538 Lübeck, Deutschland, Germany

2 School of Population Health and Environmental Sciences, Faculty of Life Sciences and Medicine, King's College London, 4th Floor, Addison House, Guy's Campus, London SE1 1UL, UK

3 Editorial Office, Graefe's Archive for Clinical and Experimental Ophthalmology, Di-Ep Biomedical Editorial Services Ltd, PO Box 5617, Glasgow, Scotland G77-9EH, UK

4 The Royal College of Ophthalmologists National Ophthalmology Database, Gloucestershire Retinal Research Group office, Above Oakley Ward, Cheltenham General Hospital, Cheltenham GL53 7AN, UK and 2019), 40 papers were accepted, 26 papers rejected, and 13 papers received the option to transfer to alternate journals since the authors were unable to revise.

An author contributes according to the following current definitions, by the International Committee of Medical Journal Editors [2] all of:

a) Acquisition, analysis, or interpretation of data,

b) Drafting the paper or revising the content,

c) Final approval of the work,

d) Responsibility, integrity, and accountability.

Statisticians who are collaborating with you will meet the criteria by:

a) Helping design the study, advising on appropriate data collection, and taking responsibility for statistical analysis - descriptive (graphs) and inferential-the time to consult a statistician is before data collection wherever possible,

b) Translating statistical methodology used in the analysisso that statistical terminology is understood by research collaborators,

c) Identifying limitations with the data and analysis and ensuring interpretation of analyses are robust, being responsible for statistical analyses and more [3],

d) Authors respond in full to statistical reviewers' comments.

The research project has more chance of proceeding well if all collaborators agree to the project plan beforehand. Many published articles need the contribution of specialists from more than one field. The benefit of reporting any statistics is obvious (see (a) above). Papers with a lack of statistics (b) or poorly integrated (c) may not be sent for external peer review. Acceptance for publication is more likely, when all specialists in the team respond to review comments (d). Are there downsides?

There may be a cost. Statisticians, like other professionals, need resourcing. You may find the statistician irritating - their tendency to stay on the fence and temper conclusions may jar. 
A classification for statistical co-authorship is described in greater detail in Statistics in Medicine [4].

Some research may necessitate the use of advanced statistics, and some projects can be lengthy; thus, more than one statistician may be required. Statisticians usually work in departments distinct from ophthalmology but with a similar inner structure and pressure to publish. Many projects could profit from a formal collaboration with two or more statisticians working on different parts of the project-e.g., preparatory work and analysis of final results-as a result being acknowledged as a named co-author in one article. In our own experience, the papers worked in collaboration with ophthalmologists, and one or two statisticians have resulted in higher citations and often higher than the journals' impact factors suggested [5]. The Journal of the American Medical Association even required analyses by independent statisticians from 2005 to 2013 [6]. Collaborations with more than one statistician may spark statistics papers with ophthalmologists as co-authors.

Peer review by statisticians has led to recommendations like the CONSORT-Statement [7]. Our presence on this journal's editorial board makes this visible. Please reciprocate the transparency. The joint work is important for validity and credibility.

We would like to take this opportunity and thank our statistical reviewers who help and support the journal with the peer review of papers. This helps in upholding the standard of the journal, and your assistance is very much appreciated.

Funding information Open Access funding provided by Projekt DEAL. This study is partly funded by the National Institute for Health Research (NIHR) Biomedical Research Centre based at the Moorfields Eye Hospital NHS Foundation Trust and the Institute of Ophthalmology at the University College London.

\section{Compliance with ethical standards}

Conflict of interest Reinhard Vonthein, Paul H J Donachie-Editorial Board members
Diana Epstein-Managing Editor, Editorial Office

Catey Bunce-Senior Statistical reviewer, Joint Lead for NIHR Statistics group, Ambassador for the Royal Statistical Society

Disclaimer The views expressed are those of the author(s) and not necessarily those of the NHS, the NIHR, the Department of Health, the Royal Statistical Society, or The Royal College of Ophthalmologists.

Open Access This article is licensed under a Creative Commons Attribution 4.0 International License, which permits use, sharing, adaptation, distribution and reproduction in any medium or format, as long as you give appropriate credit to the original author(s) and the source, provide a link to the Creative Commons licence, and indicate if changes were made. The images or other third party material in this article are included in the article's Creative Commons licence, unless indicated otherwise in a credit line to the material. If material is not included in the article's Creative Commons licence and your intended use is not permitted by statutory regulation or exceeds the permitted use, you will need to obtain permission directly from the copyright holder. To view a copy of this licence, visit http://creativecommons.org/licenses/by/4.0/.

\section{References}

1. Epstein D (2011) The delicate topic of authorship -2011 update. Graefes Arch Clin Exp Ophthalmol 249:1437-1438. https://doi. org/10.1007/s00417-011-1740-7

2. www.icmje.org accessed on 10.02 .2020

3. Zapf A, Rauch G, Kieser M (2020) Why do you need a biostatistician? BMC Med Res Methodol 20:23

4. Parker RA, Berman NG (1998) Criteria for authorship for statisticians in medical papers. Statist Med 17:2289-2299. https://doi.org/ 10.1002/(SICI)1097-0258(19981030)17:20<2289

5. Web of Knowledge. Thomson Reuters, webofknowledge.com accessed on 10.02.2020

6. Bauchner H (2013) Editorial policies for clinical trials and the continued changes in medical journalism. J Am Med Assoc 310(2):149 150. https://doi.org/10.1001/jama.2013.8083

7. CONSORT 2010 Statement. consort-statement.org accessed on 10. 02.2020

Publisher's note Springer Nature remains neutral with regard to jurisdictional claims in published maps and institutional affiliations. 